Anna Trosborg*

\title{
Translation Studies: Some Recent Developments
}

If someone asks me how I translate, I am hard put to find an answer. I can describe the physical process: I make a very rapid first draft, put it aside for a while, then go over it at a painfully slow pace, pencil - and eraser - in hand. But that is all outside. Inside the job is infinitely complex...

(Weaver (1989:119), quoted in Bell (1991:32))

\section{Background}

Much recent work in the field of translation studies derives from unease and dissatisfaction about the way translation has been treated (or not treated at all) over a substantial period of time by translation theorists and by linguists and psychologists. Translation theorists, almost without exception, have made little systematic use of the techniques and insights gained by "contemporary" linguistics over the last twenty years or so. Linguists, for their part, have at best been neutral and at worst actually hostile to the notion of a theory of translation. Applied psychology has directed little attention to translation, and so far, we know very little about the process of translation (Bell, 1991:XV). A further problem lies in the unwillingness on the part of professional translators to consider the importance of theory. Practising translators usually tend to be sceptical of any kind of theorizing (Snell-Hornby, 1988:48).

The main emphasis has been on literary translation, translation theorists have been subjective and normative, and translation theory has been harmed by "individualist anecdotalism and the tendency to issue arbitrary lists of 'rules' for the creation of 'correct' translations..." (Bell, 1991:XV).

There has been no clear conception of what translation actually is. In spite of having been a hotly debated topic for centuries, translation still seems to be a mysterious phenomenon which defies understanding and still lacks a comprehensive theory which can explain what it is and how it happens. Is it an art, a craft which defies description? Is it a sub-disci-

\footnotetext{
* Anna Trosborg

Department of English

The Aarhus School of Business

Fuglesangs Allé 4

8210 Aarhus $V(D K)$
} 
pline of applied linguistics, as has often been assumed? Is it a discipline in its own right or no discipline at all?

Vagueness and lack of clarity may arise from bewilderment concerning the term translation itself and a clear conception of what translation actually is. This problem is remedied by Bell (1991:13-15). We need to recognize the distinction between translation as (1) process, as (2) product, and as (3) concept:

(1) translating: the process (to translate; the activity rather than the tangible object);

(2) a translation: the product of the process of translating (i.e. the translated text);

(3) translation: the abstract concept which encompasses both the process of translating and the product of that process.

A theory of translation as process would draw heavily on psychology and on psycholinguistics. It requires a study of information processing comprising such topics as perception, memory, and the encoding and decoding of messages. A theory of translation as product would require a study of texts not merely by means of the traditional levels of linguistic analysis (syntax and semantics) but also by making use of stylistics and recent advances in text-linguistics and discourse analysis. Finally, a theory of translation as both process and product would require the integrated study of both and as such, it may be considered the long-term goal for translation studies (cf. Bell, 1991:26).

\section{Traditional views on translation}

The development in translation studies is inextricably involved with the changing views within the discipline of linguistics. Up to 1970, this discipline was dominated by the "appearance of transformational grammar as a serious candidate for an adequate theory of human language" (Statement of Purpose in the first issue of Linguistic Inquiry, 1971:1). Language universals were propagated by Chomsky (e.g. Chomsky, 1965) and the school of generative grammar; in principle, everything was translatable.

The generative approach to linguistics was a reaction, among other things, to the theory of linguistic relativity. According to the Sapir-Whorf hypothesis thought does not precede language, but on the contrary, it is conditioned by it. Language is influenced by culture and, ultimately, translation is impossible. 
Later transformational grammar, and to a certain extent structural linguistics in general, were found detrimental to the development of a general translation theory on the grounds that such schools of thought provided concepts and procedures inappropriate to translation. Examples are their emphasis on the formal classification of constants at the expense of variables, the restriction of study to word and sentence level, and above all, their exclusion of the study of meaning (Beaugrande, 1978:8).

Furthermore, translation studies have been hampered by classical modes of categorization, which operate with rigid dividing-lines, binary opposites, antitheses and dichotomies (Snell-Hornby, 1988:36). Consider, for example, the age-old distinction between 'faithful' and 'free', or 'literal' and 'free', later rephrased as 'semantic' vs. 'communicative' (Newmark, 1981, 1988), 'direct' vs. 'indirect' translation (Gutt, 1991). Frequently, these distinctions are mere academic constructs which paralize the finer differentiations required in all aspects of translation studies.

Translatology, as a linguistically oriented branch of translation theory was influenced by Nida (1964), a Bible translator from the U.S.A., ${ }^{1}$ and Catford (1965), England, who based his translation theory on the systemic grammar concept of the British linguist M.A.K. Halliday. Both Nida and Catford strongly advocated the central concept of equivalence in contrast to the traditional dichotomy of "faithful" vs. "free". Their view of translation was supported by later definitions:

Translation is the expression in another language (or target language) of what has been expressed in another, source language, preserving semantic and stylistic equivalences.

(Dubois (1973), in Bell's (1991) translation)

Translation is the replacement of a representation of a text in one language by a representation of an equivalent text in a second language. (Hartmann and Stork, 1972:713)

Hartmand and Stock (ibid) make it very clear that the problem of equivalence is essential, although texts in different languages can be equivalent in different degrees (fully or partially equivalent), in respect of different levels of presentation (equivalent in respect of context, of semantics, of grammar, of lexis, etc.) and at different ranks (word-for-word, phrasefor-phrase, sentence-for-sentence).

1 Literal translation, i.e. word-for-word rendering of a text was derived from Bible translation with its deep-seated belief in the sacred Word of God. Even today, there is a lot of disagreement and controvercy with regard to changing the wording of biblical texts into modern languages. 
In Germany, translation studies was for a long time considered a subdiscipline of applied linguistics, and not highly esteemed. Übersetzungswissenschaft, as the discipline was called, was characterized as no "wissenschaft" at all ("Die Sprachwissenschaft ist eine Wissenschaft ohne Sprache" (Snell-Hornby, 1988:14)).

\subsection{The notion of equivalence}

In Catford's definition (1965:20), translation was defined as "The replacement of textual material in one language (SL) by equivalent textual material in another language (TL)." Influenced by transformational grammar and contrastive linguistics, language was seen as a transcoding process involving the substitution of a sequence of equivalent units. It was the task of the translator to select the so-called optimal equivalents from the diverse "potential equivalents" of the TL (see Kade 1968, Reiss 1971, Diller and Kornelius 1978) and the sum total of target units would then render the interlingual 'tertium comparationis' expressed in the ST (Snell-Hornby, 1988:16).

It was soon discovered, however, that it was a fallacy to presuppose symmetry between languages. Linguistic items rarely show a one-to-one correspondence outside the narrow field of standardized terminology. This finding led to an explosive proliferation of equivalence types: totale Äquivalenz; fakultative Äquivalenz (one to many equivalence), e.g. German: Spannung; English: voltage, tension, suspense, stress, pressure; approximative Äquivalenz (one-to-part-of-one correspondence), e.g. German: Himmel; English: heaven, sky; dynamic equivalence, i.e. the closest natural equivalent, e.g. "The Lamb of God" -> "The Seal of God" (in Eskimo culture) (Nida, 1964); structural equivalence, i.e. equivalence at text level (Filipec, 1971). Compare also Neubert's "textbound equivalence" (1984:68, 1986:87ff.). The classification of equivalence into five types: denotativ, konnotativ, textnormativ, pragmatich, formal (Koller, 1979) represented mainly a reformulation of other equivalence types in terms of categories which are by no means clear-cut.

Equivalence was sought either between translation units (Kade, 1968) or at the level of the entire text (Wills, 1977) or both (Reiss, 1971, House, 1977).

A recent coursebook on translation (Baker, 1992) emphasizes the current preoccupation with the notion of equivalence consisting, as it does, 
of a short introduction followed by six chapters on various aspects of equivalence. ${ }^{2}$

\subsection{Criticism of the concept of equivalence}

The concept of equivalence has been questioned ever since it was first established. Due to recent work by prominent scholars in the field (Vermeer 1983, Snell-Hornby, 1988, Nord, 1991), this view of translation has undergone a radical change. Basically, Snell-Hornby's conception of translation supports the more dynamic approach pioneered by Hoenig and Kussmaul (1982), whose dominant criterion is the communicative function of the target text, which governs what they call the "notwendigen Grad der Differenzierung" (see Hoenig and Kussmaul 1982). Also Vermeer's and Nord's approaches are relative to the individual situation and hence dynamic.

In a chapter on "the illusion of equivalence", Snell-Hornby (1988:1322) explains the rationale behind the shift of emphasis from a preoccupation with equivalence to a concern about the function of the TT.

The assumption behind the claim for equivalence presupposes a degree of symmetry between languages which makes equivalence possible. ${ }^{3}$ Snell-Hornby makes evident the fallacy of this claim when comparing the English term "equivalence" with the German term "Äquivalenz". The two terms, generally taken to be "perfectly symmetrical renderings of a common interlingual tertium comparationis", differ in a number of respects (ibid pp. 16-17). In mathematical and formal logic, equivalence indicates a relationship of absolute symmetry and equality involving guaranteed reversibility, comparable to the meaning of Äquivalenz. In English the notion is used both as a sharply defined scientific term and in the notoriously fuzzy area of general vocabulary to mean "of similar significance", virtually the same thing" (OED), but it is in the latter sense that equivalence was originally used in English translation theory.

As guidelines for translators, neither is useful:

Äquivalenz - as a narrow, purpose-specific and rigorously scientific constant - has become increasingly static and one-dimensional, equivalence (leaving aside the TG-influenced concepts of the 1960s) has become

2 The six chapters are: 2 Equivalence at word level; 3 Equivalence above word level; 4 Grammatical equivalence; 5 Textual equivalence: thematic and information structures; 6 Textual equivalence: cohesion; 7 Pragmatic equivalence.

3 There is no absolute synonymy between words in the same language, so why should anyone be surprised to discover a lack of synonymy between languages (Bell, 1991:6). 
increasingly approximative and vague to the point of complete insignificance.

(Snell-Hornby 1988:21)

Also within translation didactics, equivalence is a "doomed concept". According to Hulst (1992), these scholars are subject to the same fallacy that has been attributed to Reiss: "using the source text as a standard for judging of the target text". Translation quality assessment based on a criterion of equivalence is totally opposed to the theoretical Neuorientierung, where the central concepts 'skopos' and 'target-orientedness' indicate a theoretical approach in which the ST is 'thrown off its throne' (ibid).

A less radical approach has been taken by Hatim and Mason (1990). They also reject the term equivalence on the grounds that complete equivalence is hardly an achievable goal, "as if there were such a thing as a formally or dynamically equivalent target-language (TL) version of a source-language (SL) text" (p. 8). However, according to them "the term is, of course, usually intended in a relative sense - that of closest possible approximation to ST meaning", which is a more manageable concept.

As such, they advocate 'dynamic equivalence' as a principle of equivalence of effect on the target language reader as a basic orientation (rather than as a binary choice). ${ }^{4}$

\subsection{Equivalence in specialized language (LSP) texts}

The relevance of the concept of equivalence for at least some texts, namely texts involving a high degree of specialization, has been acknowledged by Snell-Hornby. Referring to Schmitt (1986) and Arntz (1986), she states:

As a fundamental principle we may say that the simplest interlingual relationship - where the term equivalence is still justified - exists at the level of terminology and nomenclature, though even here reservations are called for.

(Snell-Hornby 1988:106)

The notion of equivalence is considered to be of some relevance for certain types of special language translation where the focus is on isolatable lexical items (ibid p. 34).

4 Equivalence in the sense of "equal effects of ST and TT" has been criticized for not being a very practicable criterion for a translation. The translator needs to know exactly which "type of effect" is required to remain unchanged (Nord 1991:140). 
However, LSP-texts involve a wide range of different genres, from manuals, brochures, advertisements to, for example, scientific texts. Compare also the variety of text genres involved by the legal register (see Trosborg, 1992:11-14). The desired degree of equivalence is likely to vary with the task in question. While the task of the legal translator is "to remain true to the ST and to approximate it as closely as possible with his translation" (Rayar 1988:542), the translator may be given a free hand when translating a brochure or a manual. A division into specialized and non-specialized texts does not provide clear indications with regard to the demand for equivalence.

A further suggestion has been that the concept of adequacy in translation is perhaps a more useful one. Adequacy of a given translation procedure can then be judged in terms of the specifications of the particular translation task to be performed and in terms of users' needs (Hatim and Mason, 1990:8). It must be borne in mind, though, that equivalence and adequacy are indeed two different concepts. 5

\subsection{The Manipulation School}

The approach of the "Manipulation School" is based on the concept of the literary polysystem going back to the Russian Formalists and the Prague Structuralists, and the Tel Aviv scholar Even-Zohar (1979) in particular. Israeli scholars claim that translations have frequently played a primary, creative and innovative role within their literary systems. The so-called Manipulation School derives from a specific approach to literature (The Manipulation of Literature) by a group of German translators, who claim that "from the point of view of the target literature, all translation implies a degree of manipulation of the source text for a certain purpose" (Hermans, 1985:9).

In this approach, translation is seen as a text type in its own right, as an integral part of the target culture and not merely as a reproduction of another text. The starting-point is the exact opposite of that represented by previous approaches: not intended equivalence but admitted manipulation (cf. Snell-Hornby, 1988:23). The emphasis on the target text leads to a primarily descriptive approach which explicitly rejects the normative

5 While equivalence refers to a relation between ST and TT (that of symmetry), the concept of adequacy concerns the text in relation to its readers. Adequacy of the TL text relates to the function of the text in terms of user's needs within TL text type norms. The distinction allows for both ST and TT to be adequate in their respective cultural settings without being equivalent. 
and evaluative attitudes of both traditional translation theory and linguistically oriented translatology. Taken to its extreme, this view of translation implies that any text is to be taken as a translation of another text if it is declared as such, and is hence to be treated by the scholar as an accepted part of the literary system. One may well wonder with Snell-Hornby (1988:25) whether the element of evaluation and judgement can ever be completely dispensed with.

The writings of the "Manipulation School" concentrate on describing and analysing translations comparing different translations of the same work on a descriptive rather than an evaluative basis (see, e.g. Lefevere, 1984, Lambert et al. 1985, Toury, 1986). See further the article by Anne Schjoldager, this volume, for a critical evaluation of the manipulation theory applied to translation and interpreting. On the basis of her own corpus of recordings of interpreting performed in interpreter training, she searches for norms and strategies.

\section{Translation as an Interdisciplinary Study}

Translation studies should not be considered a mere offshoot of another discipline or sub-discipline (whether Applied Linguistics or Comparative Literature). Both the translator and the translation theorist are concerned with a world between disciplines, languages and cultures. Still, translation is to be considered a discipline in its own right (cf. Snell-Hornby, 1988:35).

Translation study, as a subject considered worthy of serious academic study, gained impetus with the rise of disciplines such as sociolinguistics and cross-cultural studies, which view language in its infinite variability and in relation to human behaviour and perception, culture and communication (cf. the "pragmatische Wende" in Germany described by Wills (1987)). Keywords are synthesize, relate, differentiate, work empirically and inductively. These approaches are based on a world-view which synthesizes rather than separates; they do not view language as an isolated phenomenon, but relate it to the world around and to other disciplines, they adhere to culture-bound differentiation rather than universalist theories, and, finally, they work empirically and inductively with concrete langauge material (Snell-Hornby, 1988:68). In an attempt to set about providing systematic and objective descriptions of the process of translation, the need for access to and familiarity with the accumulated knowledge about the nature and function of language and the methodology of linguistic enquiry has become more and more pressing. 
The translation of older literature requires knowledge of Historical Linguistics. Contrastive Linguistics has great potential for tranlation theory, although up to now its results in this respect have been meagre (Snell-Hornby, 1988:35). Efforts have been concentrated mainly on syntax and lexicology.

When translating, it soon becomes clear that, although the meanings of words are problematic in themselves (there is no one-to-one correspondence between the items of one language and those of another), the greater problem is meaning which derives from the relationship of word to word rather than that which relates to the word in isolation (Bell, 1991:83). Concepts from traditional semantics with regard to reference theory and meaning postulates comprise distinctions such as (i) sense and reference, (ii) denotation and connotation, (iii) hyponomy, synonymy and antonymy, (iv) entailment, implicature and proposition, and (v) proposition, sentence, and utterance.

The distinction between denotative and connotative refers to meaning which is referential, objective and cognitive, and the shared property of a community, in contrast to meaning which is not referential but associational, subjective and affective, which may not be shared by the community at large. Brynja Svane, this volume, studies reference identification in translation and interpreting and points to problems involved when speakers and hearers attach different values to the same referents. Meaning postulates isolate three key types of relationship between concept and concept: inclusion (hyponomy), overlap (synonymy) and exclusion (antonymy), which vary across languages and cultures. By contrast, the Actor-Process-Goal-Instrument relationship of propositions is thought to be identical for all languages, no matter how the relationship is expressed syntactically.

Componential analysis, although disappointing as a theory which sought to isolate universal semantic features, is justified as a technique for describing at least part of the semantic system of particular languages. It is worth while considering for the translator as a means of gaining insights into the similarities and differences between languages by arriving at the so-called semantic differential of lexical items. ${ }^{6}$ Componential analysis attempts to extend the usefulness of the sign by building up lexical entries which consist of distinctive semantic features, binary in form and listed as either present or absent. ${ }^{7}$

6 For description and exemplification, see Bell (1991:100-103).

7 See, e.g. Bell (1991:88-91). 
For the translator, the text is not purely a linguistic phenomenon; it must be seen in terms of its communicative function, as a unit embedded in a given situation, and as part of a broader sociocultural background (Snell-Hornby, 1988:69). When abandoning the notion of formal competence (as outlined by Chomsky) as an adequate measure in favour of the broader model of communicative competence (see Canale, 1983), translators and translation theorists were met with greater demands. This model, which applies to all communicators, comprises not only the component of linguistic competence (lexicon, syntax and semantics), but also the component of sociolinguistic competence (pragmalinguistic and sociopragmatic competence), the component of discoursal competence, and the additional requirement of world knowledge.

Of basic importance is text-linguistics in all its aspects, from the analysis of the macrostructure, thematic progression and sentence perspective to coherence and cohesion. In addition to sociolinguistic context, the linguistic co-text is crucial. The complex relationship between translation and language-in-text has been described by Snell-Hornby as a phenomenon of "Word against Text". 8

Studies in psycholinguistics offer insight as regards the interdependence of language, experience and thought, and as regards memory and perception. Linking linguistics with psychology may serve as a useful approach to analyse the process of translation. However, few studies have attempted to explore the psycholinguistic dimension of translation. Bell (1991) sets out to repair this in his book Translation and Translating. In an attempt to understand what it is that translators do when they translate, Bell (1991) describes linguistic texture in terms of structure and discourse, and text processing in terms of construction and interpretation. Following Bassnett-McGuire (1980:37), Bell's major goal is to adopt a descriptive rather than a prescriptive approach to the investigation of the translation process in order to reach an understanding of the process undertaken in the act of translation, and, not, as is so commonly misunderstood, to provide a set of norms for effecting the perfect translation.

8 See Snell-Hornby $(1988: 47,105)$ for the differentiation between words in isolation (as they appear in dictionaries) and "words against texts", i.e. roughly the difference between the referential (objective) meaning of words and the associative (subjective) meaning of words. 


\subsection{Language and Culture}

While the classic approach to the study of language and translation has been to isolate phenomena (mainly words) and study them in depth, recent translation studies are essentially concerned with a web of relationships, the importance of individual items being decided by their relevance in the larger context of text, situation and culture (Snell-Hornby, 1988:36).

Culture is to be understood, not in the narrower sense of man's advanced intellectual development as reflected in the arts, but in the broader anthropological sense of all socially conditioned aspects of human life (cf. Hymes, 1971). The concept of culture is now prevalent in translation theory with the following aspects as salient (see Vermeer, 1986:33): (1) The concept of culture as a totality of knowledge, proficiency and perception; (2) its immediate connection with behaviour (or action) and events; (3) its dependence on norms, whether those of social behaviour or those accepted in language usage. The concept of culture as a totality of knowledge, proficiency and perception is fundamental in the approach to translation.

The acknowledgement of translation as an act of communication with emphasis on the importance of specific situational contexts call for findings from sociolinguistics, both with regard to studies of language varieties (sociolects) and, even more important, with regard to the realization of communicative acts in relation to context and situation (sociopragmatics). A promising area for future research is the field of cross-cultural pragmatics with cross-cultural studies in which speech act realizations are analysed in relation to socio-cultural constraints (e.g. Snell-Hornby, 1984). However, cultural differences may originate from any linguistic concept. By means of the category of gender, especially the concept of social gender, Uwe Kjær Nissen, this volume, illustrates the different parameters which are involved when referring to translation as an act of cross-cultural transfer.

\subsection{Special Language Translation}

With an interdisciplinary framework, the foundation has been laid for the conception of translation studies as an integrated and independent discipline covering the translation of all text genres form literay texts to general to specialized texts.

Special language translation presupposes familiarity with Language for Specific Purposes (LSP), for example with work in terminology, and 
it is facilitated by access to data-banks. A subject much overlooked in studies of the translation of LSP-texts is the study of underlying processes and rules as a prerequisite for the understanding of these texts. The translation of, for example, technical texts may require knowledge of mechanical processes. So far, very little attention has been paid to the importance of underlying semantic knowledge to translation. The article by Joel Nordborg Nielsen, this volume, is an attempt to fill this gap for technical texts.

As discussed in chapter 3, translation study draws on many disciplines, but it is not equal to the sum total of their overlapping areas. Translation is to be seen as a discipline in its own right, which is to develop its own methods within the insights of the complexities of the translation process. In chapters 4 and 5 below, we consider steps in this direction.

\section{Prototype and Gestalt}

According to traditional translation theory, the translator has the option, then, of focusing on finding formal equivalents which 'preserve' the context-free semantic sense of the text at the expense of its context-sensitive communicative value or finding functional equivalents which 'preserve' the context-sensitive communicative value of the text at the expense of its context-free semantic sense (Bell, 1991:7). In the former case, the translator may be critized for the 'ugliness' of a 'faithful' translatation, in the latter, he/she runs the risk of being criticized for 'inaccuracy' in spite of a 'beautiful' translation. The answer lies not in choosing which of the two conflicting alternatives to support, but in determining the point on the scale between them which is valid for the case in question.

With the development of text-linguistics, there has been an increasing awareness of the text as a complex, multi-dimensional structure consisting of more than the mere sum of its parts - a gestalt, whereby an analysis of its parts cannot provide an understanding of the whole:

Whereas linguistics has gradually widened its field of interest from the micro- to the macro-level, translation studies, which is concerned essentially with texts against their situational and cultural background, should adopt the reverse perspective: as maintained by the gestalt psychologists, an analysis of parts cannot provide an understanding of the whole, which must be analyzed from "the top down."

(Snell-Hornby, 1988:35) 
It is recognized that the essential characteristic of the lexical system of language is not precise boundary-marking but fuzziness, and it is this inherent fuzziness of language which presents the most formidable obstacle to the translator (Bell, 1991:102). In Snell-Hornby's approach, the dichotomy of two extremes (e.g. 'literal' vs.' free') is replaced by the prototypology, admitting blends and blurred edges, and the dichotomy gives way to the concept of a spectrum or cline against which phenomena are situated and focused. Within her model, she considers the situation of the ST, the function of the TT, and finally, the status of the ST (see Snell-Hornby (1988:110-129) for description and exemplification.

\subsection{Scenes-and-frames Semantics}

Scenes-and-frames semantics as proposed by Fillmore (1977) emphasizes the dynamic aspect of text-assimilation. Agaist a background of linguistic coding (frames), the interpreter of a text conjures up his/her own individual scenes. The term scene is to be understood as follows:

I intend to use the word scene - a word I am not completely happy with in a maximally general sense, to include not only visual scenes but familiar kinds of interpersonal transactions, standard scenarios, familiar layouts, institutional structures, enactive experiences, body image; and in general, any kind of coherent segment, large or small, of human beliefs, actions, experiences, or imaginings.

(Fillmore, 1977:63)

The idea of using Fillmore's scenes-and-frames concept in translator training originated in the work of Vannerem (cf. Vannerem and SnellHornby, 1986). The scene is the experienced or otherwise meaningful situation which finds expression in linguistic form. Scenes and frames constantly activate each other: a particular linguistic form, such as a phrase found in a text, evokes associations which themselves activate other linguistic forms and evoke further associations (cf. Snell-Hornby, 1988:80). In this way the hermeneutic approach to translation is emphasized. In Fillmore's words:

Successful text analysis has got to provide an understanding on the part of the interpreter of an image or scene or picture of the world that gets created and filled out between the beginning and the end of the textinterpretation experience.

(Fillmore, 1977:61)

Text-assimilation involves creating an inner world, and this depends considerably on the subjective experience of the reader. The translator starts 
from a presented frame (the text and its linguistic components). Based on the frame of the text, the translator-reader builds up his own scenes depending on his/her own level of experience and his/her internalized knowledge of the material concerned. The translator then creates the TT from perceived scenes, not by matching word to word, but by the holistic process of recreating a gestalt.

Compare also Bell's (1991) idea of a 'picture' which results from the process of text decoding; it is then the translator's task to communicate the picture and not the equivalent of the actual words. Bell refers to the analogy of the ice-cube (SLT) which is thawed (read) and re-frozen (translated): "The work exists in the second language as a new ice-cube different, but to all appearances the same" (Sayers Peden: 1989:13).

Translation errors may occur when the translator activates scenes that diverge from the author's intentions or deviate from those activated by the native speaker of the SL.

\section{The Skopos Theory}

The skopos theory is part of "a general theory of translation" which was first presented by Vermeer in 1978. Skopos is Greek and means aim, target. The theory hinges on the so-called "skopos rule" with its sociological sub-rule: "Human interaction (and as its subcategory: translation) is determined by its pourpose (skopos), and therefore it is a function of its purpose ..." (Nord, 1991:24).

According to the "skopos theory" (Nord 1991:8), a translation must fulfil certain requirements, which are defined by the "translation instructions" (translation assignments), in order to be suitable for a certain purpose. These instructions, which must consist of a more or less explicit description of the prospective target situation, are referred to as the "skopos", i.e. the text function of the TT.

The notion of text function means the communicative function, or the combination of communicative functions, which a text fulfils in its concrete situation of production/reception. It is derived from the specific configuration of extratextual factors comprising sender/sender's role, intention, recipient/recipient's expectation, medium, place, time, and motive (ibid p. 70). ${ }^{9}$ Translation is seen as "the production of a function-

9 Within this definition, communicative function includes information about all relevant parameters of the TL communication situation, speech act function (directive, commissive, informative, expressive, etc.) being only one of these parameters. 
al target text maintaining a relationship with a given source text that is specified according to the intended or demanded function of the target text (translation skopos)", and allows "a communicative act to take place which because of existing linguistic and cultural barriers would not have been possible without it" (Nord, 1991:28).

The function of the TT is not arrived at automatically from an analysis of the source text (ST), but it must be pragmatically defined by the purpose of the TT (ibid p. 9). Furthermore, as every TT recipient will be different from the ST recipient in at least one respect - he/she is a member of another cultural and linguistic community - functional equivalence between ST and TT is not the "normal" skopos of a translation, but an exceptional case in which the factor "change of functions" is assigned zero (ibid 23). According to this view, the initial task of the translator is to compare the (prospective) function-in-culture of the TT required by the initiator with the "function-in-culture" of the ST in order to identify those ST elements which have to be preserved or adapted in the translation. In a functional view of translation, equivalence between ST and TT is regarded as being subordinate to all possible translation scopes and not as a translation principle that is valid "once and for all" (cf. Reiss and Vermeer, 1984:146ff.)

The target recipient has a different knowledge of the world, a different way of life, a different perspective on things, and a different "text experience" in the light of which the TT is read (Nord, 1991:24). It follows that the target reader handles the text in a different way, maybe he/she is not familiar with the subject matter, or he/she needs to be "filled in" on ST specific cultural phenomena. To meet this demand, the feature of "adaptation" must be part of the concept of translation as a strategy which demands particular attention on the translator's part. The translator becomes the central figure in the process of intercultural communication.

The broader notion of function (the "skopos" of the text) is crucial. Rather than adhering to the rigid dichotomy of specialized and non-specialized text as being decisive for determining the desired degree of equivalence, it is the translator's task to consider the relevant dimensions for each individual text or text type. A crucial distinction has been made between documentary translation and instrumental translation. The TT can be seen as (a) "a document of a past communicative action in which the source culture sender made an offer of information to source culture recipient by means of a ST", or as (b) "an instrument in a new target culture communicative action, in which the target culture recepient 
receives an offer of information for which the ST served as a kind of model" (Nord, 1991:72).

Thus a documentary translation serves as a document of a source culture communication between the author and the ST recipient reproducing certain aspects of the ST or the whole ST-in-situation for the TT recipient, who is conscious of "observing" a communicative situation of which he/she is not part. An instrumental translation, by contrast, is a communicative instrument in its own right, which can focus on some features of the ST, while pushing others into the background (cf. Nord, 1991:72-73).

Translations vary in skopos, from "function-preserving" translations to "adapted translation" to "corresponding translation" (e.g. recreating a piece of literature in a different culture, a different time, etc.). Erling Wande, this volume, has used the skopos theory as the theoretical framework for his study of Finnish/Swedish community interpreting in Sweden. His findings show that "skopos rules" serve as important guidelines for interpreters.

A heightened awareness for the need for competent interpreters is recognized by Nancy Schweda Nicholson, also this volume. She gives a comprehensive report of the increasing effort invested in upgrading the competence and professionalizing the image of the community interpreter in the United States and the United Kingdom.

\section{Concluding the findings}

A strict polarized dichotomy must be abandoned in favour of a communicatively oriented approach taking into consideration translation as an instance of communication embedded within a given situation, and viewed within a broader sociocultural context.

As a result of an interdisciplinary approach with influences from the fields of linguistics and psycholinguistics, from recent developments in text-linguistics and discourse analysis, and not least directed by trends in social anthropology and the ethnography of speaking which resulted in a growing number of cross-cultural studies of speech acts, the field of translation studies has undergone a number of changes: from a preoccupation with literature to a concern with general language and specialized language; from limited text-types and rigid equivalence-types to holistic gestalt-like principles; from a concern with isolated words to text-in-situation with emphasis on cultural background. A text is no longer seen as a 
static specimen of language but as a verbalized expression of an author's intention; translation is not seen as a mere transcoding process but as a cross-cultural event. Interpretation is not supposed to take place from the micro-level of the word ("bottom-up" processing) but from the macrostructure of the text to the micro-unit of the word ("top-down" processing). Orientation towards the function of the target text (prospective translation) prevails over prescriptions of the target text (retrospective translation), and translations are regarded as as concrete assignments serving specific functions (not as model translations).

When adapting a translation, it is crucial to distinguish between changes necessitated by diverging linguistic systems, on the one hand, and changes determined by the function of the TT in agreement with the 'translation instructions' (cf. the translation skopos) received by the translator, on the other. In other words, a distinction must be made between adaptations forced on the translator by linguistic differences between SL and TL over which he/she has no control, and adaptations which the translator chooses to make in order to comply with purposes and intentions outlined in the given translation instructions. Cultural phenomena have a special status which is particularly problematic for the translator; source culture specific phenomena may have to be either preserved or "implanted" in the target culture, dependent on text genre and on the purpose of the translation.

Today, the extent to which a text is translatable is thought to vary with the degree to which it is embedded in its own specific culture, and with the distance that separates the cultural background of ST and target audience in terms of time, place, etc. (the "scale of translatability"). We should not expect theoretical models of translation to solve all the problems a translator encounters. Instead, theories should formulate a set of strategies for approaching problems and for coordinating the different aspects entailed. Finally, even though translation theory is now prospering, and great efforts are invested in translator training, translations as products may never be perfect. Even when an experienced translator 'completes' his/her 'final' version, a tiny insistent voice may still be saying: "Hang on a minute; I've got a great idea!" (cf. Bell, 1991:75)10

10 Michael Caine's famous closing words in the film The Italian Job. 


\section{References}

Arntz, Reiner (1986): Terminologievergleich und internationale terminologieangleichung. In: Mary Snell-Hornby (ed.) Übersetzungswissenschaft - Eine Neuorientierung, 283310.

Baker, Mona (1992): In other words: a coursebook on translation. London and New York: Routledge.

Bassnett-McGuire, Susan (1980): Translation studies. London: Methuen.

Bell, R. T. (1991): Translation and translating: Theory and practice. London: Longman.

de Beaugrande, Robert (1978): Factors in a theory of poetic translating. Assen: van Gorcum.

Canale, M. (1983): From communicative competence to communicative language pedagogy. In Richards, J. C. and Schmidt, R. W. Language and communication, 2-29. London: Longman.

Catford, J. C. (1965): A linguistic theory of translation. London: Oxford University Press.

Chomsky, N. (1965): Aspects of the theory of syntax. Cambridge, Mass.: MIT Press.

Diller, Hans-Jürgen and Kornelius, Joachim (1978): Linguistische Probleme der Übersetzung. Tübingen: Niemeyer.

Dubois, J. et al. (1973): Dictionnaire de linguistique. Paris: Larousse.

Even-Zohar, Itamar (1979): Polysystem theory. Poetics Today 1-2, 287-310.

Filipec, J. (1971): Der Äquivalenzbegriff und das Problem der Übersetzbarkeit. In: Beiheft V/VI der Zeitschrift Fremdsprachen, 81-85.

Fillmore, Charles J. (1977): "Scenes-and-frames semantics. In: Zampoli, A. (ed.) Linguistic Structures Processing. Amsterdam: N. Holland, 55-81.

Gutt, E. A. (1991): Translation and relevance. Cognition and context. Oxford: Blackwell.

Hartmann, R.R.K. and Stork, F.C. (1972): Dictionary of language and linguistics. Amsterdam: Applied Science.

Hatim, Basil and Mason, Ian (1990): Discourse and the translator. London/New York: Longman.

Hermans, Theo (ed.) (1985): The manipulation of literature. Studies in literary translation. London: Croom Helm.

Hoenig, Hans G. and Kussmaul, Paul (1982): Strategie der Übersetzung. Ein Lehr- und Arbeitsbuch, Tübingen: Narr.

Holtz-Mänttäri, Justa (1984): Translatorisches Handeln. Theorie und Metode. Helsinki: Suomalainen Tiedeakatemia.

House, Juliane (1977): A model for translation quality assessment. Tübingen: Narr.

Hulst, Jacqueline (1992): Translation criticism: Aim or tool? Paper presented at Translation Studies Congress, 9-12 September, Vienna, Austria.

Hymes, Dell (1971): On communicative competence. Philadelphia: University of Pennsylvania Press.

Kade, Otto (1968): Zufall und Gesetzmässigkeit in der Übersetzung. Beiheft zur Zeitschrift Fremdsprachen I, Leipzig. 
Koller, Werner (1979): Einführing in die Übersetzungswissenschaft. Heidelberg: Quelle \& Meyer.

Lambert, José, D'hulst, Lieven and van Bragt, Katrin (1985): Translated literature in France, 1800-1850. In: Hermans, T. (ed.) The manipilation of literature, 149-163.

Lefevre, André (1984): Teaching literary translation: The possible and the impossible. In: Wills, W. and Thome, G. (eds.) Translation theory and its implementation in the teaching of translating and interpreting. Tübingen: Narr, 90-97.

Neubert, Albrecht (1984): Text-bound translation teaching. In: Wills, W. and Thome, G. (eds.) Translation theory and its implementation in the teaching of translating and intyerpreting. Tübingen: Narr, 61-70.

Newmark, Peter (1981): Approaches to translation. Oxford: Pergamon.

Newmark, Peter (1988): A textbook of translation. London: Prentice Hall.

Nida, Eugene A. (1964): Toward a science of translating. With special refernce to principles and procedures involved in Bible translating. Leiden: Brill.

Nord, Christiane (1991): Text analysis in translation. Amsterdam/Atlanta: Rodopi.

Rayar, W. (1988) Problems of legal translation from the point of view of the translator. In: Nekeman, P. (ed.), XIth World Congress of FIT. Translation our Future, pp. 451462. Maastricht: Euroterm.

Reiss, Katharina (1971): Möglichkeiten und Grenzen der Übersetzungskritik. Kategorien und Kriterien für eine sachgerechte Beurteilung von Übersetzungen. München: Heuber.

Reiss, Katharina and Vermeer, Hans J. (1984): Grundlegung einer allgemeiner Translationstheorie. Tübingen: Niemeyer.

Schmitt, Peter A. (1986): Die 'Eindeutigkeit' von Fachtexten: Bemerkungen zu einer Fiktion. In: Mary Snell-Hornby (ed.) Übersetzungswissenschaft - Eine Neuorientierung, 252-282.

Snell-Hornby, Mary (1984): The linguistic structure of public directives in German and English. Multilingua 4, 201-211.

Snell-Hornby, Mary (1988): Translation studies an integrated approach. Amsterdam/ Philadelphia: John Benjamins Publishing Company.

Trosborg, Anna (1992): The performance of legal discourse. HERMES 9, 9-19.

Toury, Gideon (1986): Translating English literaturre via German - and vice versa. A symptomatic reversal in the history of modern Hebrew literature. Unpublished manuscript.

Vannerem, Mia and Snell-Hornby, Mary (1986): Die Szene hinter dem Text: 'scenes-andframes semantics' in Übersetzung. In: Snell-Hornby (ed.), Übersetzungswissenschaft - Eine Neuorientierung, 184-205.

Vermeer, Hans J. (1983): Aufsätze zur Translationstheorie. Heidelberg.

Vermeer, Hans, J. (1986): Übersetzen als kultureller Transfer,” in: Snell-Hornby, M. (ed.) Übersetzungswissenschaft - Eine Neuorientierung, 30-53.

Weaver, W. (1989): The process of translation. In: Biguenet, J. and Schulte, R. The Craft of Translation. Chicago: University of Chicago, 117-24. 
28

Wills, Wolfram (1977): Übersetzungswissenschaft. Probleme und Metoden. Stuttgart: Klett.

Wills, Wolfram (1987): Handlungstheretische und verhaltenswissenschaftiche Aspekte der Übersetzungswissenschaft. Unpublished manuscript. 